\title{
Seralarda Isıtma Sistemlerinin Projelenmesinde Gerekli Olan Isı Gücünün Belirlenmesinde Yeni Yaklaşımlar
}

\author{
Adil AKYÜZ ${ }^{1}$ A. Nafi BAYTORUN ${ }^{2} \quad$ Ali ÇAYLI $^{3}$ Sait ÜSTÜN ${ }^{1} \quad$ Derya ÖNDER $^{2}$ \\ ${ }^{1}$ K.S.Ü. Ziraat Fakültesi Biyosistem Mühendisliği Bölümü; KAHRAMANMARAŞ \\ ${ }^{2}$ Ç.Ü. Ziraat Fakültesi Tarımsal Yapılar ve Sulama Bölümü, ADANA \\ ${ }^{3}$ K.S.Ü. Türkoğlu Meslek Yüksekokulu, KAHRAMANMARAŞ \\ $\triangle$ : adilakyuz@ksu.edu.tr
}

Geliş (Received): 15.11.2016

Kabul (Accepted): 22.12.2016

\begin{abstract}
ÖZET: Seralarda ısıtma sistemlerinin projelenmesinde gerekli olan 1sı gücünün belirlenmesi sera tipine, donanımına, serada üretilen bitkinin sıcaklık isteklerine, diş iklim koşullarına ve seranın yönetimine bağlı olarak değişim göstermektedir. Seralarda 1sı gücünün belirlenmesinde gerekli olan projeleme sıcaklığı, serada arzulanan sıcaklıkla, sera kurulacak yerde son on yıl içinde en az iki kez arka arkaya ortaya çıkan en düşük sıcaklık ortalaması arasındaki fark olarak kabul edilmektedir. Bu değerlere göre belirlenen 1s1 gücü, gereksinilen maksimum 1s1 gücü değeri olup, serada tüm yıl sıcaklığın arzulanan değerde tutulmasına olanak sağlamaktadır. Ancak belirlenen maksimum isı gücüne yılın çok az bir zamanında ihtiyaç duyulmaktadır. Bu nedenle, yeni bir yaklaşım olarak, saatlik iklim değerlerinden gidilerek 1sı gücü değerinin hesaplanması, 1sıtma sisteminin daha gerçekçi olarak projelenmesi sağlayabilecektir. Yapılan bu çalışmada, saatlik iklim değerlerini kullanarak hesaplama yapan ISIGER uzman sistem yazılımı yardımıyla, gece/gündüz $16 / 21^{\circ} \mathrm{C}$ iç sıcaklık değeri için Antalya ili yerel iklim değerlerine göre (sıcaklık, radyasyon ve rüzgâr hızı) gereksinilen 1sı gücü değerleri belirlenmiştir. Bu değerler en düşük sıcaklık ortalamasına göre hesaplanan ısı gücü değerleri ile karşılaştırılmıştır. Hesaplamada meteoroloji işleri genel müdürlüğüne ait uzun yıllık veriler kullanılmıştır.

Elde edilen sonuçlara göre; ISIGER uzman yazılımı ile belirlenen 1sı gücü, en düşük sıcaklık değerine göre yapılan hesaplama değerinden \%11 daha az bulunmuştur. Bu sonuçlar, özellikle ısıtma sistemi yatırımlarının projelenmesinde ilk yatırım giderlerinden ve enerji tüketiminden tasarruf etme imkânı olduğunu göstermektedir.
\end{abstract}

Anahtar Kelime: Sera, seralarda 1sitma, sera isı gereksinimi

\section{New Approaches to Required Heat Power for Designing the Greenhouse Heating Systems}

ABSTRACT: The determination of heat power required to design the heating systems in the greenhouses varies depending on the type, the equipment and the temperature requirements, the external climatic conditions and the management of the greenhouse. The projecting temperature required to determine the heat power in some places is considered to be the difference between the desired temperature in the greenhouse and the lowest average temperature that occurs consecutively at least twice in the last decade. This determined heat power is the required maximum heat power value which allows the whole year temperature to be kept at the desired value in the greenhouse. However, this determined maximum heat power is needed in a very short time of the year. For this reason, as a new approach, calculation of the heat power value by taking the hourly climate values may enable the heating system to be designed more realistically.

In this study, the required heat power values according to the local climatic values (temperature, radiation and wind speed) of Antalya province for $16 / 21^{\circ} \mathrm{C}$ day/night indoor temperature were determined with ISIGER expert system software that calculates using the hourly climate values. These values are compared with the heat power values, which calculated by the lowest temperature average. Long-term official data are used for the calculation.

Results indicated that the heat power determined by ISIGER expert software was found to be $11 \%$ less than the calculation based on the lowest temperature value. These results show that it is possible to save on initial investment costs and energy consumption, especially in designing heating system investments.

Keywords: Greenhouse, greenhouse heating, greenhouse heat requirements

\section{GİRIŞ}

Türkiye'de seracılık 1940 yıllarında ilk defa Akdeniz bölgesinde özellikle Antalya'da başlamış, buradan ekolojik koşullara bağımlı bir gelişme göstererek Ege ve Marmara bölgelerine yayılmıştır. Günümüzde örtü altı yetiştiriciliği en yoğun olarak Akdeniz bölgesinde yapılmaktadır. Akdeniz Bölgesi içerisinde yer alan Antalya ilimiz toplam 22000 hektar ile ülkemiz toplam örtü altı varlığının \%37'sini oluşturmaktadır. Büyük yatırımcı gruplarının da sektöre girmesiyle hızlı bir gelişim gösteren modern seracılık, son on y1llık süreci göz önüne aldığımızda büyük bir gelişme göstererek günümüzde 1000 ha seviyelerine ulaşmıştır. Bu rakama her yıl yaklaşık 150-200 ha alan eklenmektedir. 66000 ha örtü altı alanımızın 31000 ha yüksek örtü altı sistemleri olarak tanımlanan seralardan oluşmaktadır (TUİK, 2015). Mevcut örtü altı varlığımızın. \%82'si Akdeniz sahil şeridinde, \%10'u Eğe bölgesinde, \%8'i de diğer bölgelerdedir. Akdeniz sahil şeridindeki seraların \%40'1 Antalya'da, \%24'ü Mersin'de, \%15'i Adana'da, 
\%5'i Muğla'da,\%5'i İzmir ve Aydın'da ve \%11'i diğer illerdedir (Büyüktaş ve ark., 2016). Günümüzde sera alanlarımızın \%3'ünde modern seracılık yapılmaktadır. Önümüzdeki on yıllık süreçte bu payın \%15 seviyelerine ulaşması hedeflenmektedir.

Seracılıktaki yeni gelişmeler bu sektörde sürdürülebilirliği sağlamaya yönelik gayretler ile paralel olarak ortaya çıkmaktadır. Seraların yapısal özelliklerinin iyileştirilmesi, iklimlendirme ve alternatif enerji kaynaklarından faydalanma, kontrollü koşullarda üretim, topraksız tarımın yaygınlaştırılması, entegre hastalık ve zararlı yönetimi, sertifikalı güvenli ve izlenebilir g1da üretimi şeklinde özetlenebilir. Seralarda

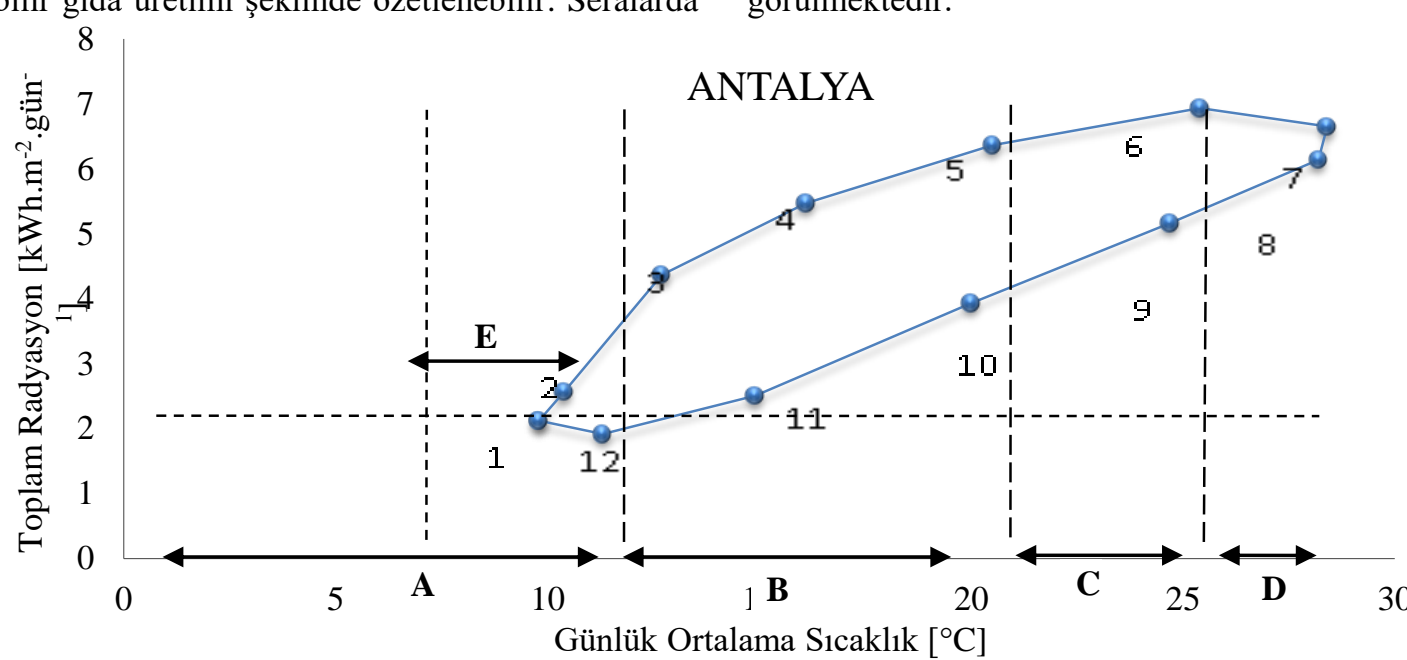

Şekil 1: Antalya ili uzun yıllık ortalama sıcaklık ve günlük radyasyon değerleri, (A) Isıtma gerekli, (B) Havalandırma gerekli, (C) Sürekli havalandırma ve/veya soğutma gerekli, (D) Serada üretim yapılamaz, (E) Sadece gece saatlerinde isitma gerekli.

Ancak bu aylarda ortalama sicaklık değerleri $7^{\circ} \mathrm{C}$ 'nin altına düşmediğinden, üretici bu bölgemizde soğuk seracılığ1 tercih etmekte, ekstrem günlerde ise basit önlemlerle üretimin devamlılığını sağlamaya çalışmaktadır (Baytorun ve ark., 2000; Baytorun ve ark., 1994).

Isıtılmayan seralarda en büyük sorun düşük sıcaklığa bağlı ortaya çıkan yüksek nemdir. Seralarda yüksek nem nedeniyle ortaya çıkan hastalıklara karşı aşırı kimyasallar kullanılmaktadır. Engindeniz ve ark. (2010) yaptıkları çalışmada, Türkiye'de seralarda 2850 g.da-1 ilaç kullanıldığını ifade etmektedir. $\mathrm{Bu}$ miktar seralarda kullanılan ortalama değerlerin çok üstündedir. Isıtılmayan seralarda aşırı ilaç kullanımı, tüketici sağlığını ve çevreyi olumsuz yönde etkilemektedir. Seralarda düşük sıcaklık ve yüksek nem sorununu çözmek için alınabilecek önlemlerden biri de 1sıtmadır. Düşük sıcaklık ve yüksek nem bir yandan fiziksel, kimyasal ve aromatik kalite noksanlığı oluştururken, diğer yandan yoğun tarımsal savaş ilacı ve hormon kullanımını zorunlu kılmaktadır. Seralarda nitelikli ve nicelikli verimin elde edilebilmesi için günlük ortalama diş sıcaklığın $12^{\circ} \mathrm{C}$ 'nin altına düşmesi durumunda 1sıtma zorunluluğu vardır (von Zabeltitz, 1994).

Seralarda ısıtmaya karar vermeden önce, seçilen 1sıtma sisteminin doğru olarak projelenmesi, enerji tasarrufu ve ilk yatırım giderlerinin azaltılması açısından büyük bir öneme sahiptir. Seralarda 1sıtma sisteminin seçimi ve projelenmesinde, her şeyden önce sera kurulacak yerin büyümeyi etkileyen en önemli faktörlerden biri sıcaklıktır. Günlük ortalama sıcaklığın $7-12^{\circ} \mathrm{C}$ arasında bulunmas1 durumunda seralarda sadece gece saatlerinde 1sitma yapmak yeterli olmaktadır (Nisen ve ark., 1988). Bitkiler örtüaltı yetiştiriciliğinde özellikle $17-27^{\circ} \mathrm{C}$ arasındaki ortalama sıcaklıklara adapte olmuşlardır. Optimal sıcaklıklar geceleri $15-20^{\circ} \mathrm{C}$, gündüzleri ise 22$28^{\circ} \mathrm{C}$ arasında değişmektedir (Castilla ve Hernandez, 2007).

Şekil 1'de seracılığın yoğun olarak yapıldığı Antalya ili uzun yıllık ortalama sicaklık değerlerinin, Aralık, Ocak ve Şubat aylarında $12^{\circ}$ C'nin altında olduğu görülmektedir 
sistemlerinin daha gerçekçi değerlere göre projelenmesine olanak sağlayacaktır.

Serada saatlik değerlerden gidilerek 1S1 gücü değerlerinin hesaplanması, ISIGER (Baytorun ve ark., 2016) uzman sistemi yardımı ile yapılmıştır. Geliştirilen bu programa göre saatlik 1s1 gücü gereksinimlerinin hesaplanmasında minimum sıcaklık değerleri yerine, 1sıtmasız serada güneş enerjisine bağlı ortaya çıkan sıcaklık ve seranın enerji depolama özelliğine bağlı olarak gece saatlerinde ortaya çıkan sıcaklık yükselmeleri dikkate alınmaktadır.

$\mathrm{Bu}$ çalışmada ISIGER uzman sistemi yazılımıyla, seralarda saatlik iklim değerlerine (sıcaklık, radyasyon ve rüzgâr hızı) bağlı olarak, gereksinilen 1sı gücü değerleri, minimum sicaklık ortalamalarına göre hesaplanan 1sı gücü değerleri ile karşılaştırılarak, yöntemlerin uygunluğu belirlenmeye çalışılmıştır.

\section{MATERYAL ve METOT}

Seralarda 1s1 gücü gereksinimi, DIN 4701 standardına göre Eşitlik 1 yardımı ile hesaplanır (Tantau, 1983).

$$
Q=A_{H} * u^{\prime} *\left(\vartheta_{i}-\vartheta_{a}\right) \quad A_{H}=A_{G} * F
$$

Eşitlikte:

Q :Toplam 1sı gücü gereksinimi [W]

AH : Sera dış yüzey örtü alanı $\left[\mathrm{m}^{2}\right]$

AG : Sera taban alanı $\left[\mathrm{m}^{2}\right]$

$F \quad$ :Örtü yüzeyi faktörü

$\mathrm{u}^{\prime} \quad$ :Toplam Isı gereksinim katsayısı $\left[\mathrm{W} . \mathrm{m}^{-2} \cdot \mathrm{K}^{-1}\right]$

$\vartheta_{i} \quad$ : Serada arzulanan iç sıcaklık değeri $\left[{ }^{\circ} \mathrm{C}\right]$

$\vartheta_{a}$ : Sera kurulan yerin en düşük ortalama dış sicaklık değeri $\left[{ }^{\circ} \mathrm{C}\right]$

Eşitlik 1'de kullanılan toplam 1sı gereksinim katsayısı, seranın tipine, kullanılan örtü malzemesine, dış iklim koşullarına, serada kullanılan ısıtma ve sulama sisteminin tipine bağlı olarak değişim göstermektedir. Çizelge 1'de farklı örtü malzemesi ile kaplanmış ve 1sı korunumu amacıyla farklı önlemlerin alındığ 1 seralar için, $4 \mathrm{~m} . \mathrm{s}^{-1}$ rüzgâr hızında toplam 1s1 gereksinim katsayıları verilmiştir (von Zabeltitz, 2011).
Çizelge 1. Farklı örtü malzemelerinin toplam 1S1 gereksinim katsayıları.

\begin{tabular}{|l|l|}
\hline $\begin{array}{l}\text { Örtü malzemesi ve 1s1 } \\
\text { koruma amaçlı malzeme }\end{array}$ & $\begin{array}{l}\mathrm{u}^{\prime} \text { değeri (W.m- } \\
2 . \mathrm{K}-1)\end{array}$ \\
\hline Tek katlı cam & $6,0-8,8$ \\
\hline Tek katlı PE plastik & $6,0-8,0$ \\
\hline Çift katlı cam & $4,2-5,2$ \\
\hline $\begin{array}{l}\text { Çift katlı sert plastik } \\
\text { PMMA 16 mm }\end{array}$ & $4,2-5,0$ \\
\hline Çift katlı PE plastik & $4,0-6,0$ \\
\hline $\begin{array}{l}\text { Isı perdeli tek kat cam veya } \\
\text { plastik sera }\end{array}$ & $3,2-4,8$ \\
\hline
\end{tabular}

Serada çatı ve yan duvarlarda farklı örtü malzemesinin kullanılması durumunda, her örtü malzemesinin alanı ve 1 s 1 gereksinim katsayıları dikkate alınarak, Eşitlik 2 yardımı ile ağırlıklı ortalamaya göre, seranın toplam 1sı gereksinim katsayısı hesaplanmıştır. Serada çatı ve yan duvarlarda farklı örtü malzemesinin kullanılması durumunda, çatı ve yan duvar alanlarının, sera taban alanına oranı dikkate alınmalıdır.

$$
u^{\prime}=\frac{A_{1} * u_{1}^{\prime}+A_{2} * u_{2}^{\prime}+\ldots \ldots .+A_{n} * u_{n}^{\prime}}{A_{1}+A_{2}+\ldots \ldots . . A_{n}}
$$

Çizelge 2'de yay çatılı plastik seralarda yan duvar yüksekliğine ve taban alanına bağlı olarak örtü yüzey faktörü verilmiştir.

Is1 gücü gereksiniminin hesaplanmasında kullanılan toplam 1sı gereksinim katsayısı $\left(u^{\prime}\right)$ rüzgâr hızına bağ lı olarak değişim göstermektedir. Toplam 1sı gereksinim katsayısının rüzgâr hızına bağlı değişimi Eşitlik 3 ile belirlenmiştir (Rath, 1992).

$$
u^{\prime}=u+\frac{u}{x_{1}} *\left(x_{2} * v_{w}+x_{3}\right)
$$

Eşitlikte;

$x_{1}=7,56$

$x_{2}=0,35 \mathrm{~m} \cdot \mathrm{s}^{-1}$

$x_{3}=-1,4$

$u=4 \mathrm{~m} \cdot \mathrm{s}^{-1}$ rüzgâr hızında toplam 1sı gereksinim

\begin{tabular}{|c|c|c|c|c|c|c|c|c|c|c|}
\hline \multirow{2}{*}{$\begin{array}{l}\text { Bölme } \\
\text { Sayısı }\end{array}$} & \multirow{2}{*}{$\begin{array}{c}\text { Sera } \\
\text { Taban } \\
\text { alanı }\end{array}$} & \multicolumn{9}{|c|}{ Örtü Yüzey Faktörü F(-) } \\
\hline & & \multicolumn{3}{|c|}{ Yan Duvar 3 m } & \multicolumn{3}{|c|}{ Yan Duvar 4 m } & \multicolumn{3}{|c|}{ Yan Duvar 5 m } \\
\hline Adet & $\mathbf{m}^{2}$ & $\begin{array}{c}\text { Ön+Yan } \\
\text { cephe }\end{array}$ & Çatı & Toplam & $\begin{array}{c}\text { Ön+ } \\
\text { Yan } \\
\text { cephe }\end{array}$ & Çatı & Toplam & $\begin{array}{c}\text { Ön+Yan } \\
\text { cephe }\end{array}$ & Çatı & Toplam \\
\hline 3 & 1035 & 0,48 & 1,37 & 1,85 & 0,62 & 1,37 & 1,99 & 0,76 & 1,37 & 2,13 \\
\hline 6 & 2070 & 0,34 & 1,37 & 1,71 & 0,43 & 1,37 & 1,80 & 0,51 & 1,37 & 1,89 \\
\hline 9 & 3105 & 0,29 & 1,37 & 1,66 & 0,36 & 1,37 & 1,73 & 0,43 & 1,37 & 1,81 \\
\hline 12 & 4140 & 0,27 & 1,37 & 1,64 & 0,33 & 1,37 & 1,70 & 0,39 & 1,37 & 1,77 \\
\hline 15 & 5175 & 0,25 & 1,37 & 1,62 & 0,31 & 1,37 & 1,68 & 0,37 & 1,37 & 1,74 \\
\hline 20 & 6900 & 0,24 & 1,37 & 1,61 & 0,29 & 1,37 & 1,66 & 0,35 & 1,37 & 1,72 \\
\hline 30 & 10350 & 0,22 & 1,37 & 1,59 & 0,27 & 1,37 & 1,64 & 0,32 & 1,37 & 1,69 \\
\hline 30 & $20700 *$ & 0,13 & 1,37 & 1,50 & 0,16 & 1,37 & 1,53 & 0,18 & 1,37 & 1,56 \\
\hline
\end{tabular}
katsayıs1 $\left[\mathrm{W} \cdot \mathrm{m}^{-2} \cdot \mathrm{K}^{-1}\right]$

Çizelge 2. Sera alanı ve yan duvar yüksekliklerine bağlı olarak örtü yüzey alanı faktörü.

Yay çatılı plastik sera, bölme genişliği 6,9 m, yay yüksekliği 2,75 m, sera uzunluğu 50 m. (*) Sera uzunluğu 
Eşitlik 1'de $\vartheta_{i}$ serada arzulanan sıcaklık değeri olarak alınırken, $\vartheta_{a}$ değeri uzun yıllar ortaya çıkan en düşük sıcaklık ortalaması olarak alınmıştır. Çizelge 3 'te Türkiye'de iklim ve enerji kaynakları açısından seracılığa uygun bazı illerin, uzun yıllık ortalama en düşük sıcaklık değerleri verilmiştir.

Çizelge 3. Bazı illerin uzun yılık ortalama minimum sıcaklık değerleri (Anonim, 2015).

\begin{tabular}{|l|c|l|c|}
\hline İller & Ortalama $\vartheta_{a-} \min \left({ }^{\circ} \mathrm{C}\right)$ & İler & Ortalama $\vartheta_{a-} \min \left({ }^{\circ} \mathrm{C}\right)$ \\
\hline Adana & 5,5 & Kahramanmaraş & 1,2 \\
\hline Antalya & 5,9 & Kütahya & $-3,2$ \\
\hline Aydın & 4,3 & Mersin & 6,3 \\
\hline Balıkesir & 1,2 & Muğla & 1,6 \\
\hline Bursa & 1,6 & Ordu & 3,8 \\
\hline Çanakkale & 3,2 & Samsun & 4,1 \\
\hline Denizli & 2,2 & Sinop & 4,6 \\
\hline Diyarbakır & $-2,3$ & Şanlıurfa & 2,2 \\
\hline İzmir & 5,8 & Yalova & 3,2 \\
\hline Hatay & 4,7 & & \\
\hline
\end{tabular}

\section{ISIGER uzman sistem yazılımı}

Seralarda 1S1 gücü gereksiniminin ISIGER uzman sistemle saatlik değerlere göre hesaplanmasında Eşitlik 4 kullanılmıştır (Rath, 1992). Eşitlikte görüleceği gibi hesaplamada bölgede ortaya çıkan en düşük sıcaklık ortalaması yerine, 1sitılmayan serada güneş radyasyonuna ve seranın enerji depolama potansiyeline bağlı olarak ortaya çıkan sıcaklık yükselmesi dikkate alınarak 1sı gücü gereksinimi saatlik olarak belirlenmiştir. Isıtılmayan serada güneş radyasyonuna bağlı olarak ortaya çıkan gerçek iç sıcaklık değeri $\left(\vartheta_{i, o H}\right)$ ile seranın enerji depolama özelliğine bağlı olarak serada ortaya çıkan sıcaklık yükselmesi değerleri $\left(\Delta \vartheta_{s p}\right)$ Rath (1992)'nin belirlediği ilişkilere göre hesaplanmıştır.

$Q=\sum_{n=1}^{8760}\left(\left(\vartheta_{i_{n}}-\vartheta_{i, o H_{n}}-\Delta \vartheta_{s p_{n}}\right) * u^{\prime} * A_{H} *\left(1-E E_{E S_{n}}\right) * t_{s i}\right)(4)$

Eşitlikte;

$Q \quad:$ Yllık 1sı enerjisi gereksinimi [Wh]

$\vartheta_{i} \quad$ :Serada arzulanan sicaklık [ $\left.{ }^{\circ} \mathrm{C}\right]$

$\vartheta_{i, O H}$ :Isıtılmayan serada ortaya çıkan sıcaklık [ ${ }^{\circ} \mathrm{C}$ ]

$\Delta \vartheta_{s p}$ :Güneş radyasyonuna bağlı serada ortaya çıkan sıcaklık yükselmesi $\left[{ }^{\circ} \mathrm{C}\right]$

$u^{\prime} \quad$ :Toplam $1 \mathrm{~s} 1$ gereksinim katsayıs $\left[\mathrm{W} \cdot \mathrm{m}^{-2} \cdot \mathrm{K}^{-1}\right]$
$A_{H}$ :Örtü yüzey alanı [m2]

$E E_{E S_{n}}$ :Enerji tasarrufu amaciyla kullanılan teknik önlemin tasarruf oranı

$\mathrm{N}$ : Yilın saatleri

$t_{s i} \quad$ : Simulasyonda zaman dilimi $(1 \mathrm{~h})$

ISIGER uzman yazılımı İnternet üzerinden erişilebilen, PHP ve Javascript programlama dilinde yazılmış bir web uygulamasıdır. Hesaplamalar için kayıt giriş ekranından sonra sera türü ve özelliklerinin seçilmesi ile hesaplamalar yapılabilmektedir. Hesap sonuçları grafiksel olarak ve rapor şeklinde alınabilmektedir. Yazılım ekran görüntüsü Şekil 2'de verilmiştir.

Yapılan çalışmada Antalya ilinde kurulan seralarda 1S1 gücünün belirlenmesi için gerekli olan iklim parametreleri, Meteoroloji Genel Müdürlüğünden 19802007 yılları için sağlanmıştır. Hesaplamalar Çizelge 5'te verilen iller için yapılmıştır. Hesaplamalarda sera iç ortam sicaklık değerlerinin $\left(16 / 21^{\circ} \mathrm{C}\right)$ belirlenmesinde (gece $16^{\circ} \mathrm{C}$, gündüz $21^{\circ} \mathrm{C}$ ), domates bitkisinin optimum sıcaklık değerleri göz önünde bulundurulmuştur. 


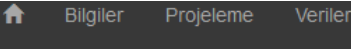

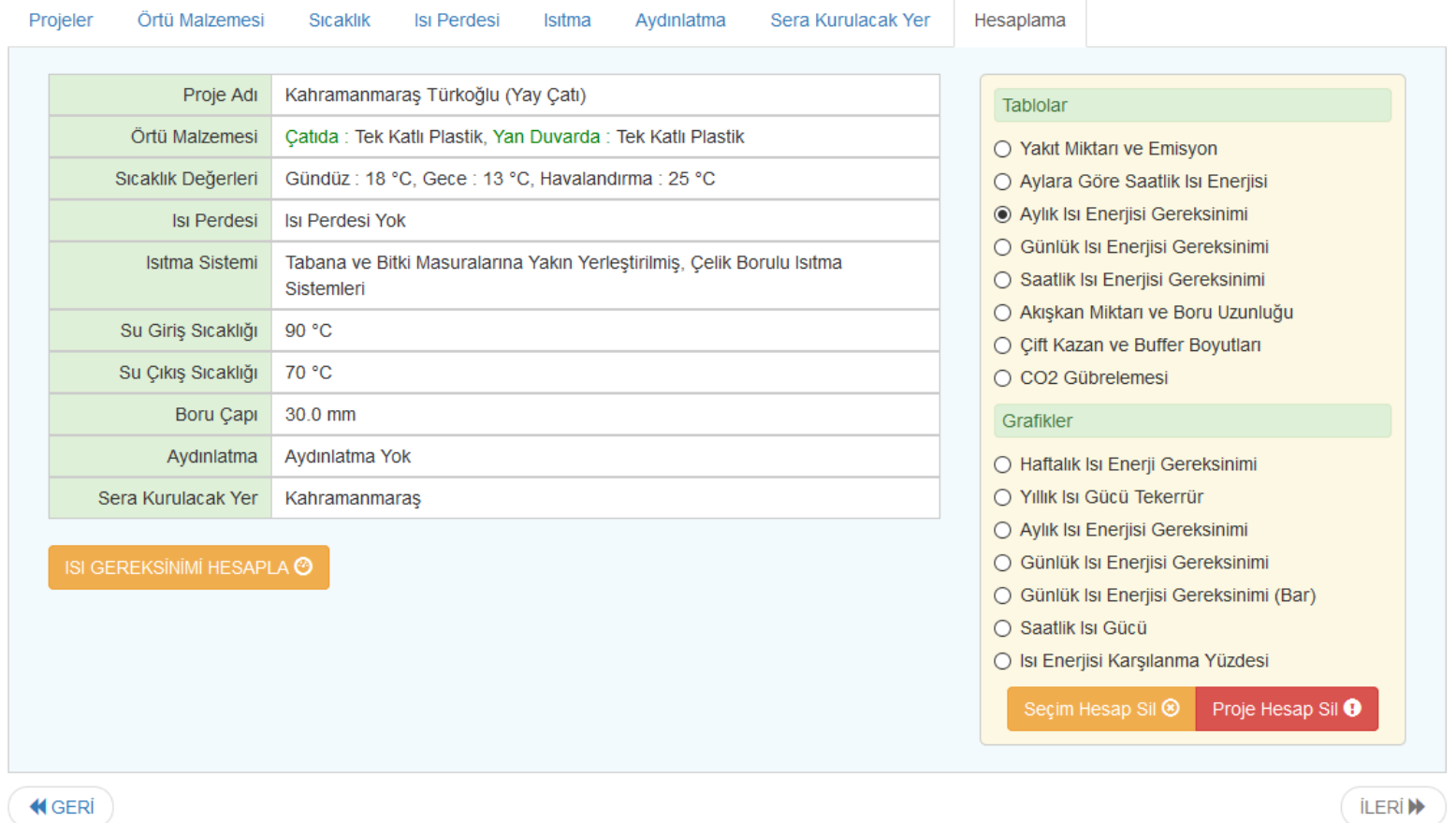

Şekil 2. ISIGER uzman yazılım ekran görüntüsü

\section{BULGULAR ve TARTISMA}

Seralarda 1S1 gücü gereksiniminin belirlenmesinde kullanılan minimum sicaklık ortalaması ve saatlik sıcaklık değerlerine bağlı olarak ISIGER uzman sistemle hesaplanan 1S1 gücü değerleri karşılaştııılmalı olarak Çizelge 4'te verilmiştir. Çizelge 4'ten de görüleceği gibi, ortalama minimum sicaklık değerlerine göre hesaplanan 1S1 gücü değerleri, saatlik iklim verilerine (sıcaklık, radyasyon, rüzgâr hızı) göre ISIGER uzman sisteme göre hesaplanan değerlerden ortalama $\% 11$ oranında büyüktür. Ortaya çıkan bu farklılık 1sı gücünün ortalama minimum sıcaklık değerine göre hesaplanmasında, toplam ısı gereksinim katsayısına etki eden rüzgâr hızının dikkate alınmamasından kaynaklanmaktadır. Çizelge 4'te de görüleceği gibi ortalama minimum sıcaklık değerine göre 1S1 gücünün hesaplanmasında, rüzgâr hızının dikkate alınması durumunda, elde edilen değerler, saatlik değerlere göre elde edilen değerlerden sadece $\% 2$ farklılık göstermektedir. Her iki yönteme göre yapılan hesaplamalarda ortaya çıkan farklar, illere göre değişim göstermektedir.

Bu sonuçlar her iki yönteme göre yapılacak 1sı gücü gereksinim hesaplarının kabul edilebileceğini göstermektedir. Seralar için belirlenen bu değerler maksimum 1s1 gücü değerleridir. Bu değerlere göre yapılan projelemelerde yıl içinde serada arzulanan sıcaklık değerleri hiç bir riske sokulmadan karşılanmaktadır. Ancak seralarda maksimum isı gücüne yllın çok az bir zamanında ihtiyaç duyulmaktadır. Belirtilen nedenle seralarda 1sı gücünün hesaplanması kadar, ortaya çıkan ısı gücü gereksinimlerinin yıl içindeki tekerrürlerinin bilinmesi, sistemin boyutlandırılması ve ilk yatırım giderlerinin düşürülmesi açısından büyük bir önem arz etmektedir.

Şekil 3'de Antalya iklim koşullarında 1sı perdeli ve 1S1 perdesiz PE plastik serada, gece/gündüz sicaklık değerlerinin $16 / 21^{\circ} \mathrm{C}$ 'de tutulması durumunda, gerekli olan 1s1 gücü gereksinimleri, yılın saatlerine bağlı olarak verilmiştir. Şekilden de görüleceği gibi serada yılın 2650 saatinde 1sıtmaya ihtiyaç duyulmaktadır. Bu koşullarda serada ortaya çıkan maksimum 1S1 gücü gereksinimi 92 W.m-2 olmaktadır. Ancak bu değere yılın çok az bir zamanında $(1 \mathrm{~h})$ ihtiyaç duyulmaktadır. Serada ısıtma sisteminin planlanmasında gerekli olan 1sı gücü $80 \mathrm{~W} . \mathrm{m}$ 2 alındığında yılın 1sıtmaya ihtiyaç duyulan (2650-59) 2591 saatinde iç sıcaklık $16 / 21^{\circ} \mathrm{C}$ 'de tutulabilecektir. Bu koşullarda yılın 59 saatinde iç sıcaklık $16 / 21^{\circ} \mathrm{C}$ 'nin altında seyredecektir.

$\mathrm{Bu}$ durum 1s1 perdeli seralarda daha anlaml bir değişim göstermektedir. Şekil 3'de 1s1 perdeli PE plastik serada iç sicaklığın $16 / 21^{\circ} \mathrm{C}$ 'de tutulmak istenmesi durumunda, saatlik değerlerden gidilerek yapılan hesaplamalara göre, gereksinilen maksimum 1s1 gücü gereksinimi 90 W.m-2 olmaktadır. Ancak bu değere yılın sadece bir saatinde ihtiyaç duyulmaktadır. Isı perdeli bu serada yılın 87 saatinde $50 \mathrm{~W} . \mathrm{m}-2$ 'den büyük 1s1 gücüne ihtiyaç duyulurken, geri kalan isıtma zamanının tümünde $(2650-87=2563 \mathrm{~h})$ ihtiyaç duyulan 1 sı gücü $50 \mathrm{~W} . \mathrm{m}-2$ ile karşılanabilecektir. 
Çizelge 4. Farklı illerde serada $16^{\circ} \mathrm{C}$ sıcaklık değerleri için ortalama en düşük sıcaklık ve saatlik sıcaklık değerlerine göre hesaplanan 1sı gücü değerleri $\left(\mathrm{W} \cdot \mathrm{m}^{-2}\right)$.

\begin{tabular}{|c|c|c|c|c|c|c|c|}
\hline \multirow{2}{*}{ İl } & \multicolumn{3}{|c|}{ Isı Gücü Gereksinimi (W.m²) } & \multicolumn{2}{|c|}{$\begin{array}{c}\text { Oransal farklılık } \\
\%\end{array}$} & \multirow[t]{2}{*}{$\begin{array}{c}\text { Ort. } \\
\text { Minimum } \\
\text { sicaklık }\left({ }^{\circ} \mathrm{C}\right)\end{array}$} & \multirow[t]{2}{*}{$\begin{array}{c}\text { Rüzgâr } \\
\text { hızl } \\
\left(\mathbf{m}^{-1} \mathbf{s}^{-1}\right)\end{array}$} \\
\hline & 1 & 2 & 3 & 4 & 5 & & \\
\hline Adana & 109,0 & 96,2 & 93,5 & 17 & 3 & 5,5 & 1,47 \\
\hline Antalya & 104,8 & 102,0 & 100,4 & 4 & 2 & 5,9 & 3,43 \\
\hline A.Karahisar & 201,4 & 185,7 & 183,7 & 10 & 1 & $-3,4$ & 2,33 \\
\hline Aydin & 121,4 & 108,9 & 111,6 & 9 & -2 & 4,3 & 1,77 \\
\hline Balıkesir & 153,6 & 144,3 & 141,8 & 8 & 2 & 1,2 & 2,70 \\
\hline Bursa & 149,5 & 138,3 & 133,8 & 12 & 3 & 1,6 & 2,39 \\
\hline Çanakkale & 132,9 & 134,8 & 127,2 & 4 & 6 & 3,2 & 4,33 \\
\hline Denizli & 143,2 & 125,1 & 123,4 & 16 & 1 & 2,2 & 1,27 \\
\hline Diyarbakır & 189,9 & 172,0 & 171,5 & 11 & 0 & $-2,3$ & 1,97 \\
\hline Hatay & 117,3 & 95,5 & 105,8 & 11 & 3 & 4,7 & 2,44 \\
\hline İzmir & 105,9 & 102,8 & 101,8 & 4 & 1 & 5,8 & 3,39 \\
\hline K.Maraş & 153,6 & 133,1 & 133,3 & 15 & 0 & 1,2 & 1,12 \\
\hline Kırşehir & 209,7 & 189,1 & 191,8 & 9 & -1 & $-4,2$ & 1,89 \\
\hline Kütahya & 199,3 & 176,4 & 175,4 & 14 & 1 & $-3,2$ & 1,53 \\
\hline Manisa & 134,9 & 121,9 & 118,8 & 14 & 3 & 3,0 & 1,92 \\
\hline Mersin & 100,7 & 90,8 & 86,8 & 16 & 5 & 6,3 & 1,89 \\
\hline Muğla & 149,5 & 136,5 & 136,6 & 9 & 0 & 1,6 & 2,13 \\
\hline Nevşehir & 206,6 & 191,9 & 188,5 & 10 & 2 & $-3,9$ & 2,48 \\
\hline Ordu & 126,6 & 113,2 & 111,4 & 14 & 2 & 3,8 & 1,71 \\
\hline Samsun & 123,5 & 111,9 & 111,9 & 10 & 0 & 4,1 & 1,97 \\
\hline Sinop & 118,3 & 117,5 & 115,2 & 3 & 2 & 4,6 & 3,85 \\
\hline Şanlıurfa & 143,2 & 125,6 & 124,0 & 15 & 1 & 2,2 & 1,35 \\
\hline Tekirdağ & 145,3 & 138,9 & 132,9 & 9 & 5 & 2,0 & 3,06 \\
\hline Yalova & 132,9 & 121,0 & 112,6 & 18 & 7 & 3,2 & 2,08 \\
\hline \multicolumn{4}{|c|}{ ORTALAMA } & 11 & 2 & & \\
\hline
\end{tabular}

(1) Ortalama minimum sıcaklık değerlerine göre hesaplanmış $\left(v_{w}=4 m \cdot s^{-1}\right)$, (2) Ortalama minimum sıcaklık ve rüzgâr hızına göre hesaplanmış, (3) Saatlik değerlere göre hesaplanmış, (4) Birinci ve üçüncü sütunlar arasındaki oransal fark, (5) İkinci ve üçüncü sütunlar arasındaki oransal fark

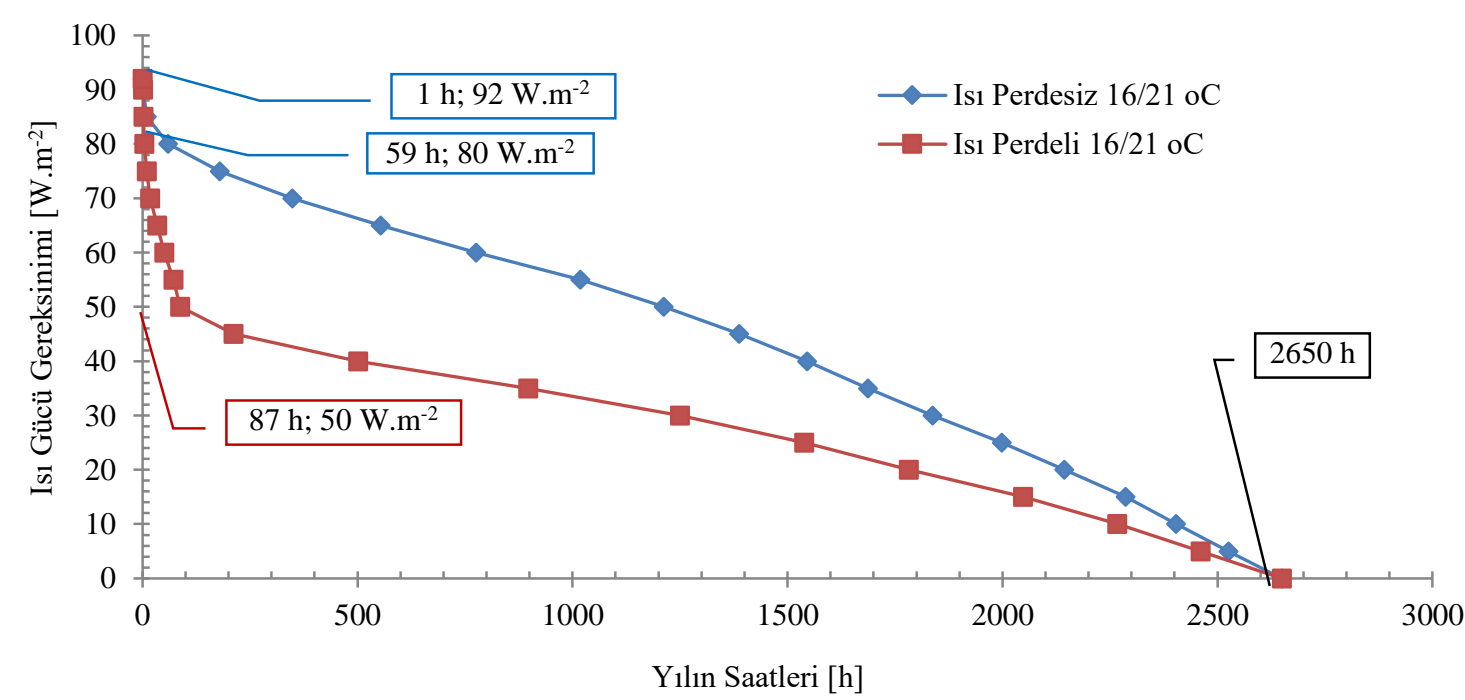

Şekil 3. Antalya ili iklim koşullarında normal ve $1 s$ k korumalı plastik serada gece/gündüz $16 / 21^{\circ} \mathrm{C}$ sıcaklık değerleri için ortaya çıkan 1sı gücü tekerrürleri (Havalandırma sıcaklığ $126^{\circ} \mathrm{C}$ ). 
Akdeniz sahil şeridinde uzun yıllık ortalama sıcaklık değerleri $7^{\circ} \mathrm{C}$ 'nin altına düşmediğinden, serada gündüz saatlerinde 1sıtma gereksinimi ortaya çıkmamaktadır. Bu sebeple serada gerekli olan 1sı gücüne, gece sıcaklık değerleri etki etmektedir. Şekil $4^{\prime}$ ten de görüleceği gibi serada sıcaklığın gece/gündüz $16 / 16^{\circ} \mathrm{C}$ 'den, $16 / 22^{\circ} \mathrm{C}^{\prime}$ ye yükseltilmesi durumunda, yılın 1sitma ihtiyacı duyulan büyük çoğunluğunda 1sı gücü değeri değişmezken, 1sıtma süresi artmaktadır. Ancak gece sicaklık değerlerinin $13^{\circ} \mathrm{C}$ ye düşürülmesi durumunda, hem ssıtma zamanında, hem de gereksinilen 1sı gücü değerlerinde büyük bir azalma meydana gelmektedir.

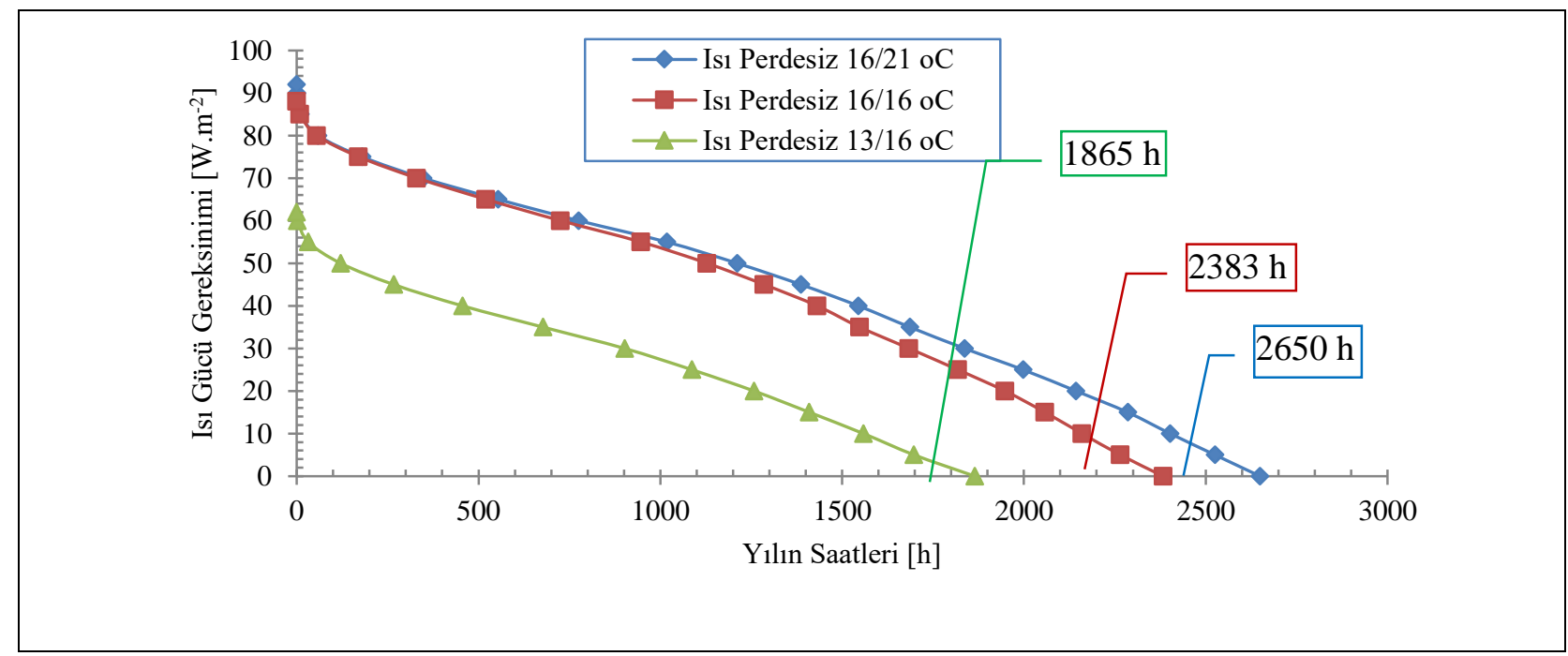

Şekil 4. Antalya ili iklim koşullarında 1sı perdesiz PE plastik serada farklı iç sıcaklık değerlerinde ortaya çıkan 1sı gücü tekerrürleri (Havalandırma sıcaklığ $26^{\circ} \mathrm{C}$ ).

Gerekli olan 1sı gücünün belirlenmesinde, serada kullanılan teknik donanımın dikkate alınması önem arz etmektedir. Şekil 5'te Antalya iklim koşullarında, sicaklığın $\quad$ gece/gündüz $\quad 16 / 21^{\circ} \mathrm{C}$, havalandırma sicaklığının $26^{\circ} \mathrm{C}$ olarak belirlendiği isı perdeli ve perdesiz PE plastik seralarda, farklı ısı gücüyle karşılanan yıllık 1sı enerjisi yüzdeleri verilmiştir.

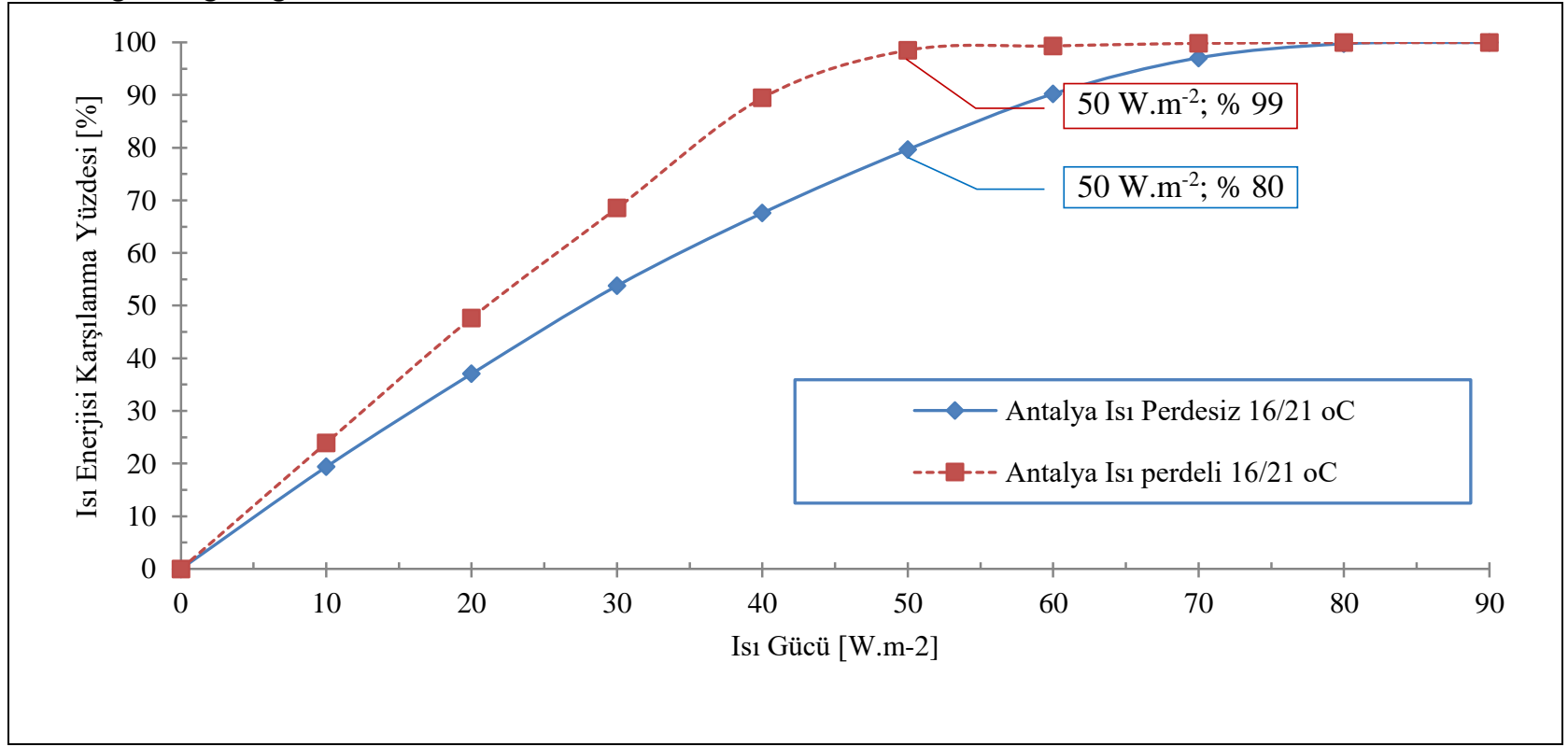

Şekil 5. Antalya ili iklim koşullarında tabana yakın 1sıtma sistemine sahip normal ve 1sı perdeli PE plastik serada gece/gündüz $16 / 21^{\circ} \mathrm{C}$ iç sıcaklık değerlerinde farklı 1sı gücü ile gerekli 1sı enerjisinin karşılanma yüzdesi (Havalandırma sicaklığ $26^{\circ} \mathrm{C}$ ). 
Şekilden de görüleceği gibi, Antalya iklim koşullarında ısı perdeli ve perdesiz PE plastik serada, üretim periyodu boyunca gerekli olan 1S1 enerjisinin karşılanabilmesi için, seçilecek sistem kapasitesi 90 W.m-2 olmalıdır. Serada kurulacak 50 W.m-2'lik 1s gücüne sahip bir 1sıtma sistemiyle, 1sı perdeli PE plastik serada sicaklığın gece/gündüz $16 / 21^{\circ} \mathrm{C}^{\prime}$ de tutulduğu koşullarda, gerekli olan 1s1 enerjisinin \% $\quad 99^{\prime} \mathrm{u}$ karşılanırken, 1Sı perdesiz PE plastik serada, yıllık 1S1 enerjisi gereksiniminin \% 80'i karşılanabilmektedir. Diğer bir ifade ile 1sı perdesiz PE plastik serada, üretim periyodu boyunca 1sitma ihtiyacı duyulan saatlerinin \%
80 'inde iç sıcaklık $16 / 21^{\circ} \mathrm{C}$ 'de tutulabilirken, geri kalan $\% 20$ 'sinde iç sıcaklık bu değerlerin altında seyredecektir. Is1 perdeli serada durum biraz daha farklı olmaktadır. Sıcaklığın $16 / 21^{\circ} \mathrm{C}^{\prime}$ de tutulmak istendiği PE plastik serada $90 \mathrm{~W}$.m-2'lik 1s1 gücüne sahip 1sıtma sisteminin seçilmesi durumunda, y1llık 1sı enerjisi gereksiniminin $\%$ 100 'ü karşılanabilmektedir. Isı gücünün \% 50 oranında düşürülmesi durumunda, yıllık 1s1 enerjisinin \% 95'i karşılanabilmektedir. Diğer bir ifade ile 1sı korumalı seralarda, azalan 1sı gücü ile gereksinilen enerji arasındaki oran, 1sı korumasız seradaki orandan oldukça büyüktür.

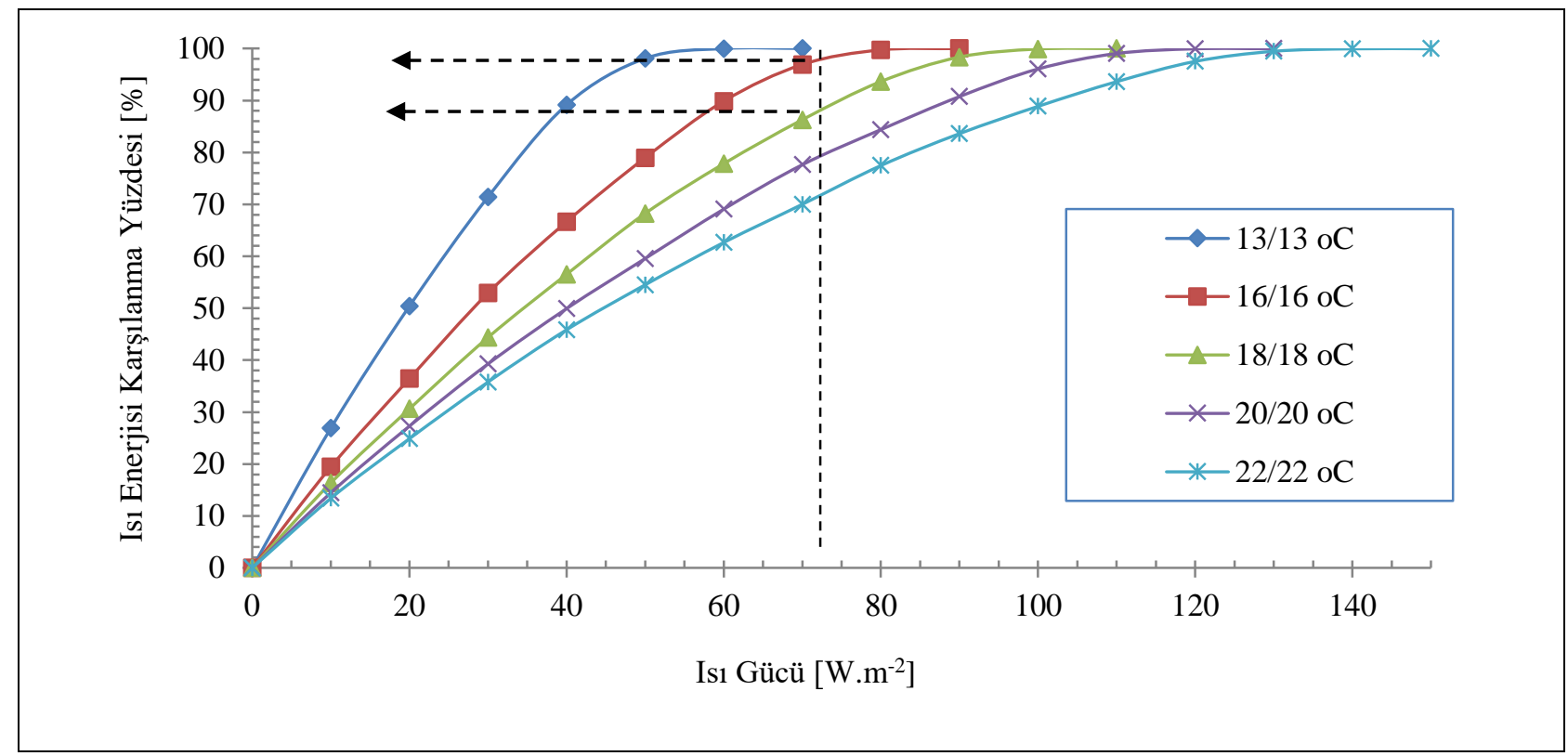

Şekil 6. Antalya ili iklim koşullarında ısı korumasız PE plastik serada farklı iç sıcaklık değerlerinde gereksinilen ısıtma gücü ile yıllık 1sı enerjisinin karşılanma yüzdesi.

Şekil 6'te Antalya iklim koşullarında tek katlı PE plastik ile örtülmüş serada farklı iç sıcaklık değerleri için, farklı 1S1 gücü ile karşılanan y1llık 1sı enerjisi yüzdesi verilmiştir. Şekilden de görüleceği gibi, Antalya koşullarında iç sıcaklığın gece/gündüz $16^{\circ} \mathrm{C}$ 'de tutulmak istenmesi durumunda gereksinilen 1 s1 gücü 90 W.m-2 olmaktadır. Isıtma sisteminin bu değere göre projelenmesi durumunda, yıl içinde ortaya çıkan en düşük sicaklık değerlerinde, serada sıcaklık $16^{\circ} \mathrm{C}$ 'de tutulabilecek ve bunun için gereksinilen 1sı enerjisinin $\% 100$ 'ü karşılanabilecektir. Seçilen 1sı gücünün düşürülmesi, ilk yatırım maliyetlerini azaltacağı gibi, enerji tasarrufu da sağlayacaktır. Antalya iklim koşullarında 70 W.m-2'lik 1sı gücüne sahip 1sıtma sisteminin bulunduğu 1Sı perdesiz PE plastik serada, iç sıcaklığın $18^{\circ} \mathrm{C}$ 'de tutulmak istenmesi durumunda, yıllın ısıtma ihtiyacı duyulan süresinin $\% 86$ 'sında serada
S1caklık $18^{\circ} \mathrm{C}$ 'de tutulabilirken geri kalan $\% 10$ 'unda $16^{\circ} \mathrm{C}$ ve $\% 4^{\prime}$ ünde $13^{\circ} \mathrm{C}$ olarak seyredecektir.

Antalya iklim koşullarında $5000 \mathrm{~m} 2$ büyüklüğündeki 1sı perdeli PE plastik serada, sıcaklığın gece/gündüz $16 / 21^{\circ} \mathrm{C}^{\prime}$ de tutulması durumunda, gerekli olan 1 sı gücü $(\mathrm{kW})$ ve yıllık 1sı enerjisi gereksinimi (MWh) Şekil 7'de verilmiştir. Şekilden de görüleceği gibi, serada iç sıcaklığın $16 / 21^{\circ} \mathrm{C}^{\prime}$ de tutulmak istenmesi durumunda, gerekli olan güç $450 \mathrm{~kW}$ olurken, seranın toplam 1s1 enerjisi gereksinimi 377 MWh olmaktadır. Bu işletmede, ihtiyaç duyulan temel isı enerjisi $150 \mathrm{~kW}$ 'lı 1 sıtma sistemiyle karşılandığında, yıllık 1Sı enerjisinin 306 MWh'1 karşılanabilecektir. Sera işletmesinde kurulacak 450 kW'l1k ikinci bir kazan, ekstrem durumlarda devreye girerek seranın maksimum 1si enerjisi gereksinimini karşılayabilecektir. 


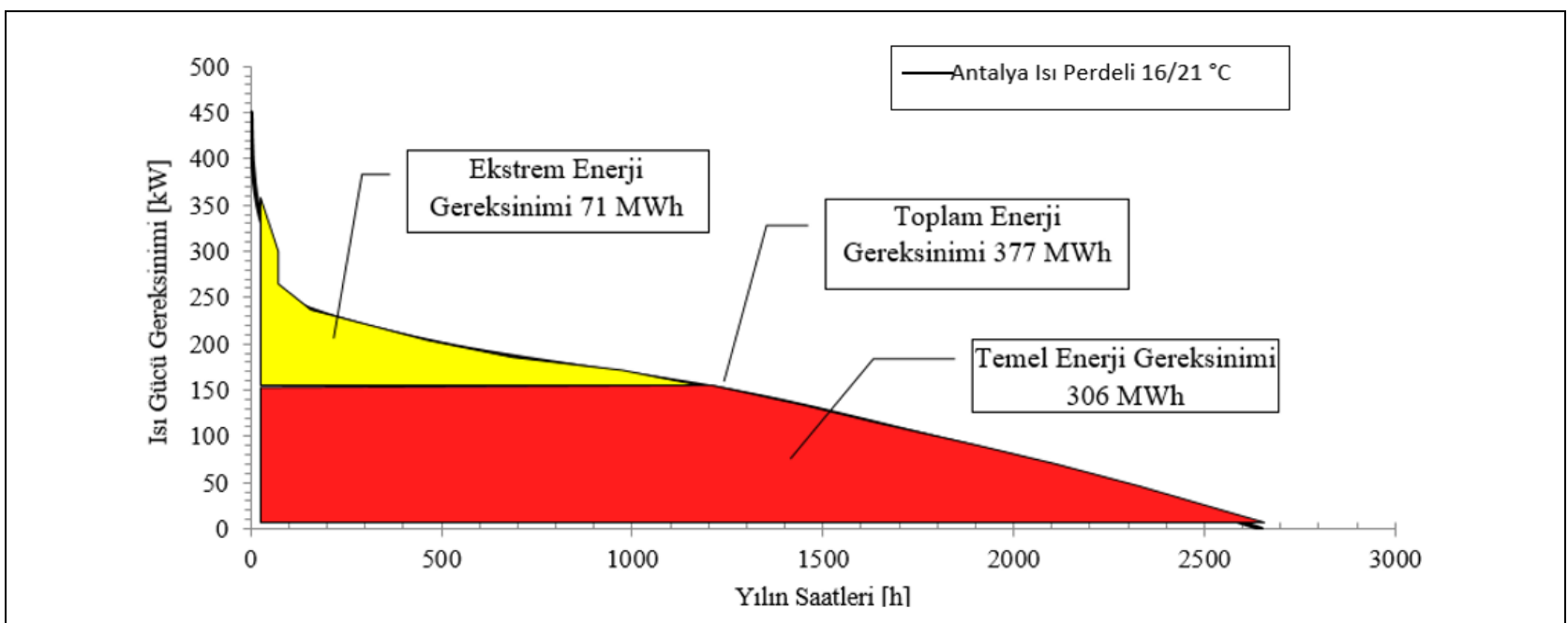

Şekil 7. Antalya ili iklim koşullarında $5000 \mathrm{~m}^{2}$ büyüklüğünde $1 \mathrm{~s} 1$ perdeli serada gece/gündüz sıcaklık değerlerinin $16 / 21^{\circ} \mathrm{C}$ 'de tutulması durumunda gerekli olan 1s1 yükü ve toplam 1sı enerjisi gereksinimi.

\section{SONUC}

Yapılan bu çalışmada serada 1sıtma sisteminin projelenmesinde gerekli olan 1sı gücünün belirlenmesi, bölgede ortaya çıkan en düşük sıcaklık ortalamasına ve saatlik değerlere göre hesaplanarak karşılaştırılmıştır. Elde edilen sonuçlara göre rüzgâr hızının dikkate alınması koşulu ile her iki yönteme göre belirlenen 1S1 gücü hesaplamaları arasında büyük bir fark bulunmamaktadır. Ancak hesaplanan bu değerler, serada ortaya çıkan maksimum 1sı gücüdür ve yılın çok az bir zamanında bu güce ihtiyaç duyulmaktadır. Bu sebeple, serada 1sıtma sistemlerinin projelenmesinde ilk yatırım masraflarının düşürülebilmesi amacıyla birbirinden ayrı kontrol edilebilir, iki ayrı ısıtma sistemi kurulmalıdır. Kurulan sistemlerden biri, seranın temel 1si enerjisi gereksinimini karşılarken, diğeri çok soğuk günlerde devreye girerek maksimum ısı ihtiyacını karşılayacaktır. $\mathrm{Bu}$ nedenle seralarda birbirinden ayrı yönetilebilir iki ayrı sistemin kurulması, ekstrem durumlarda ürünün riske edilmemesi için tavsiye edilebilir.

\section{KAYNAKLAR}

Anonim 2015. Uzun y1llik iklim verileri, devlet meteoroloji İşleri genel müdürlüğü.

Baytorun AN (2000). Seralar (çeviri). Adana: Çukurova Üniversitesi Ziraat Fakültesi Ofset atölyesi.

Baytorun AN, Akyüz A, Üstün S 2016. Seralarda 1sıtma sistemlerinin modellemesi ve karar verme aşamasında bilimsel verilere dayalı uzman sistemin "isiger-sera" geliştirilmesi. TÜBİTAK 1140533 nolu proje.

Baytorun AN, Akyüz A, Zaimoğlu Z 2000. Seralarda iklimlendirme. Paper presented at the 2. Uluslararas1 Turfanda Şurası, Anamur.

Baytorun AN, Tokgöz H, Üstün S, Akyüz A. 1994. Seralarda iklimlendirme olanakları. Paper presented at the 3. Soğutma ve İklimlendirme Kongresi, Çukurova Üniversitesi, Adana.
Büyüktaş K, Atılgan A, Tezcan A 2016. Tarımsal Üretim Yapıları. Süleyman Demirel Üniversitesi, Ziraat Fakültesi Yayın No:101. Isparta.

Castilla N, Hernandez J 2007. Greenhouse technological packages for high quality production. Acta Horticulturae: International Society for Horticultural Science (ISHS), Leuven, Belgium.

Engindeniz S, Yılmaz İ, Durmuşoğlu E, Yağmur B, Eltez RZ, Demirtaş B, Tatarhan AH 2010. Sera sebzelerinin karşılaştırmalı girdi analizi. Ekoloji, 19(74), 122-130.

Nisen A, Grafiadellis M, Jiménez R, La Malfa G, Martínez-García P, Monteiro A, Denis J 1988. Cultures protégées en climat méditerranéen. Rome: Organisation des Nations unies pour l'alimentation et l'agriculture.

Rath T 1992. Einsatz wissensbasierter systeme zur modellierung und darstellung von gartenbautechnischem fachwissen am beispiel des hybriden expertensystems hortex. Gartenbautechnische Informationen (Germany). no. 34.

Tantau HJ 1983. Heizungsanlagen im gartenbau.Handbuch des erwerbsgärtners., 258.

TUIKK 2015. Niteliklerine göre örtü altı tarım alanları Turkiye İstatistik Kurumu. Ankara.

von Zabeltitz C 1986. Gewachshauser- handbuch des erwerbsgartners Handbuch des Erwerbsgartners. Stuttgart: Ulmer -Verlag,

von Zabeltitz C 1994. Effective use of renewable energies for greenhouse heating. Renewable Energy, 5(1-4), 479-485. doi: Doi 10.1016/09601481(94)90419-7

von Zabeltitz C 2011. Integrated greenhouse systems for mild climates: Climate conditions, design, construction, maintenance, climate control. Integrated Greenhouse Systems for Mild Climates: Climate Conditions, Design, Construction, Maintenance, Climate Control, 285-311. doi: 10.1007/978-3-642-14582-7_12 